\title{
The Inaugural SHALDRIL Expedition to the Weddell Sea, Antarctica
}

\section{Introduction}

In 1994, a group of scientists began discussing a number of important scientific questions that could be addressed by drilling a series of short cores on the Antarctic continental shelf. The group adopted the name SHALDRIL, for SHALlow DRILling, and soon learned that the technology for high-quality sampling of the upper few hundred meters of the stratigraphic column was still lacking.

After more than a decade of discussion and several years of detailed planning, SHALDRIL sailed from Punta Arenas, Chile, in March 2005. The objectives of this first SHALDRIL cruise are to demonstrate the feasibility of drilling from an icebreaker platform into the Antarctic continental shelf and to obtain cores from three different sedimentary sequences that previously have not been sampled.

The principal objective of SHALDRIL originally was to monitor technological developments in shallow drilling from conventional icebreaking research vessels. In 2000, the SHALDRIL steering committee learned about new and improved drilling systems that can core through gravelly glacial deposits in water depths of several hundred meters and to subbottom depths of a few hundred meters (SHALDRIL Steering Committee, 2001). These systems can be operated from the icebreaking research vessel
Nathaniel B. Palmer (Fig. 1); thus, the long-term project has now entered the next phase of testing this proven drilling technology aboard a U. S. Antarctic Program vessel.

\section{Technology}

In 2003, a contract was signed with Seacore Ltd. (U.K.) to conduct the drilling operations for SHALDRIL. This choice was made after evaluating all of the companies then operating shallow coring systems, and it was based on the capabilities of heave-compensated rig systems, sampling tools, mobility, availability, and cost. The rig built for SHALDRIL is called the R-50 (Fig. 2) and is similar to, but slightly smaller than, the rig used recently on IODP Expedition 302 in the Arctic (ACEX), also built by Seacore. The rig is completely modular and can be rapidly mobilized as container freight. The rig has the capacity to take 100 $\mathrm{m}$ of core in up to $1000 \mathrm{~m}$ of water and longer cores in shallower water. The SHALDRIL rig has a $3-\mathrm{m}$ heave compensator that will allow drilling to continue in any type of seas in which people can realistically work, and it will be mounted over a moonpool in the starboard deck of the Palmer (Fig. 3). The position of the rig close to midship will help minimize heave as compared to drilling over the stern. The moonpool will protect the drillstring from stray bits of floating ice and will ensure that ice does not accumulate in the moonpool during drilling.

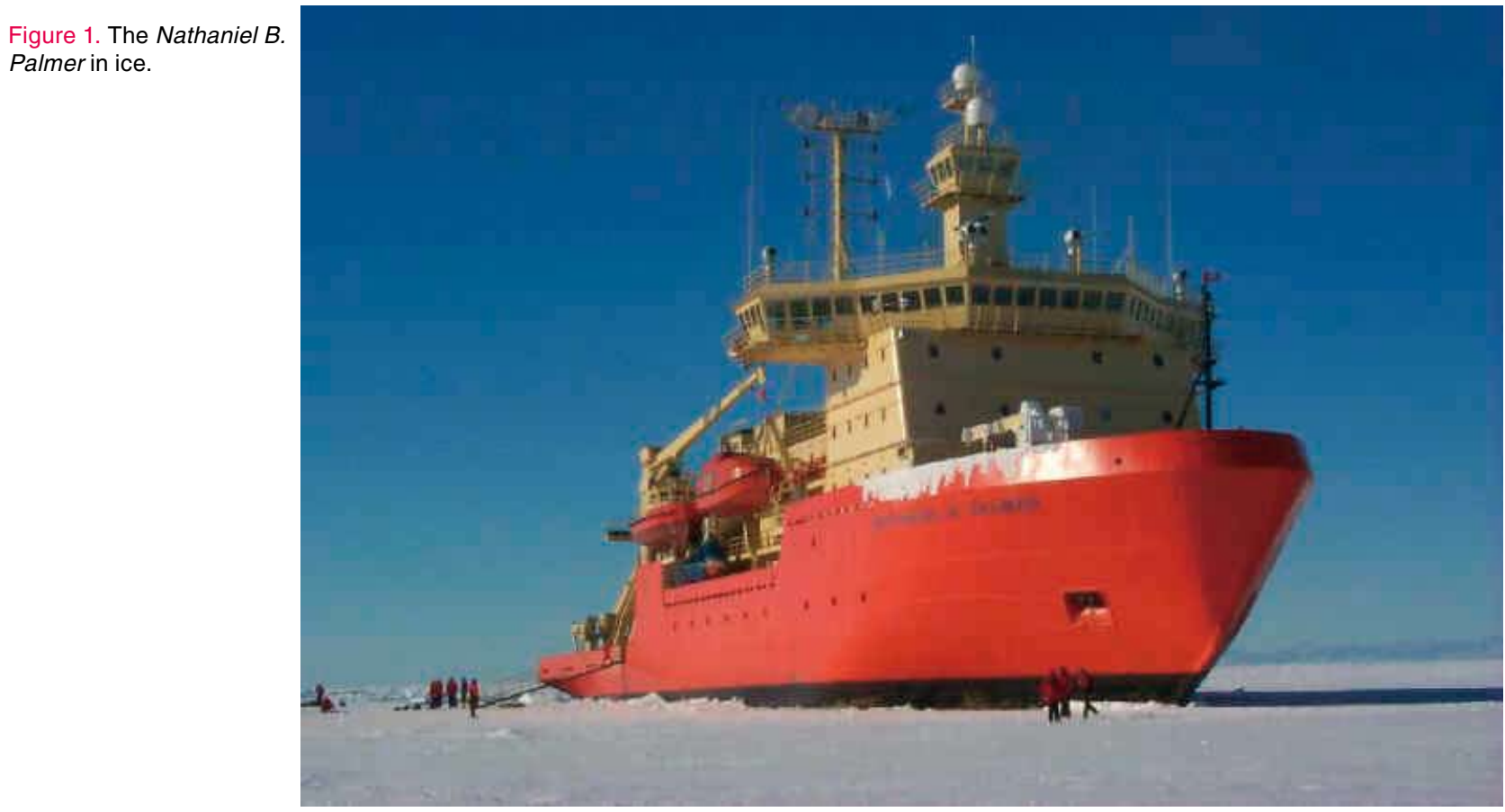


The process of planning to install the R-50 rig onto the Palmer brought with it many unexpected problems. The major hurdle was that the rig adds so much mass at heights above deck that the vessel would not meet damagestability criteria defined by the U.S. Coast Guard. After analyses by several naval architects and tests performed on the ship, additional ballast was installed to allow the R-50 rig to be safely mounted on board.

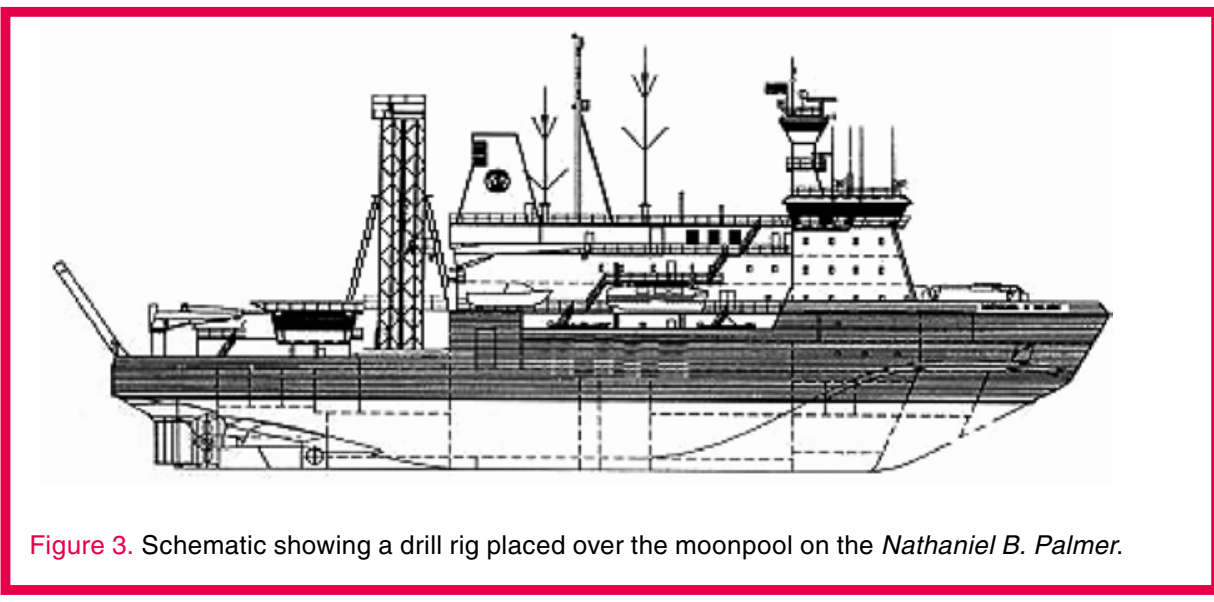

The sampling tools for SHALDRIL are being provided by the British Geological Survey (BGS) through a subcontract to Seacore. Most of the tools that will be used are part of the older BGS system, not the new tools used as part of ACEX. Piggyback coring hardware may be used in harder lithologies, although it is not the preferred technology for this program because of the time required to pull out of a hole and the likely presence of icebergs in the area. The other

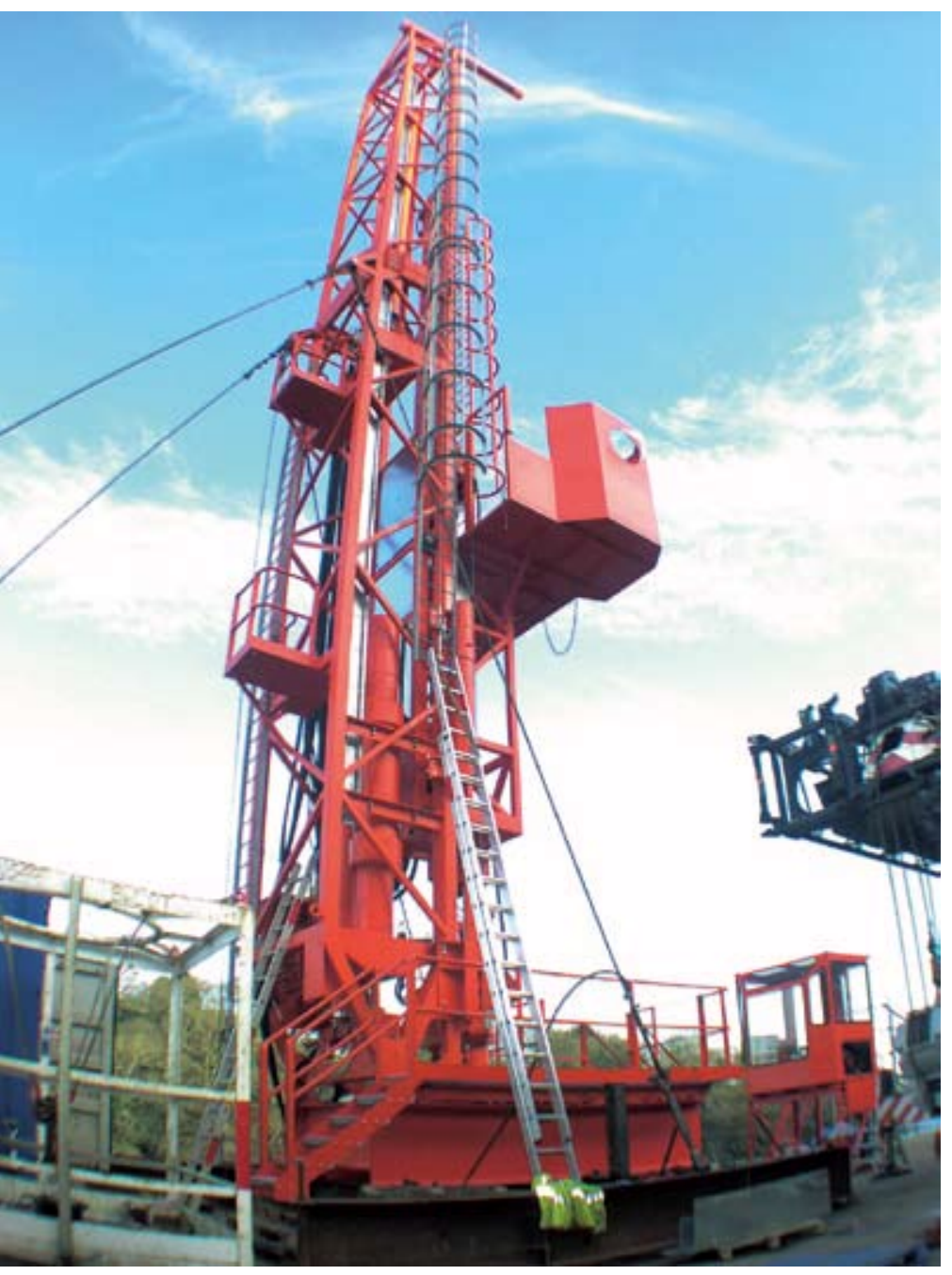

Figure 2. The R-50 rig assembled in the Seacore yard in Cornwall. sampling tool available for SHALDRIL is a Shelby-tube system especially modified for this cruise to accept liners and allow higher quality sampling of very soft materials.

The Palmer was not designed with drilling in mind and had to have its positioning system upgraded to make open-water drilling feasible. These upgrades have included the lease of a differential Global Positioning System (GPS) from Fugro-McClelland, the purchase of a single-seafloorbeacon relative positioning system, and new software for ship handling. The vessel now meets dynamic positioning (DP) system Class 0 criteria. The system has been tested, at least in part, but its full functionality will be used for the first time during SHALDRIL. The SHALDRIL strategy of taking a series of relatively short drill cores ( 100 m each) is based in part on the limits of ship handling, as well as on the unavoidable fact that icebergs may limit time at any one station.

The 31 March 2005 start date is far later in the austral summer season than ideal, but resulted in part from technical obstacles such as the need to modify the ship structurally, as well as the general demands for ship time from many different parties. Years ago, the SHALDRIL group discussed planning the project for the austral winter or close to it, and using fast ice to stabilize the vessel. Knowledge gained from other high-latitude drilling operations and from DP specialists led the program away from this option in favor of open-water drilling operations. Fast ice could stabilize the ship and might still be used in some cases, but relying on the right ice conditions (truly fast ice without any movement over many days, yet still thin enough to allow entry and safe exit) is riskier than relying on open water.

\section{Scientific Objectives}

The area best suited for this phase of the program is the James Ross Basin, located in the northwestern Weddell Sea region, offshore of Seymour Island (Fig. 4). This is the area initially identified by the SHALDRIL group as having shallow drilling targets of great scientific value, existing 
site-survey data, closest proximity to ports of departure and return, and proximity to auxiliary sites of scientific value.

The principal objective of this initial drilling leg is to test the drilling system using the Nathaniel B. Palmer, but the acquired core will have high scientific value. The first hole will be drilled into the Vega Drift (Fig. 4), an expanded section of Holocene deposits. This site was selected as the first to be drilled because it lies in the deepest and most protected water and, hence, is logistically the most feasible for testing the new drilling system. The Vega Drift site is the closest to shore and the most protected from inclement weather that typically moves eastward across the Antarctic Peninsula before reaching the drilling area. The lithology at this site, however, may be more difficult to sample with the standard suite of tools. Relatively soft, diatomaceous muds and occasional gravelly dropstones are expected throughout the total estimated coring depth of $100 \mathrm{~m}$. The modified Shelby-tube sampler was designed for this site to obtain the high-quality core needed to construct a detailed record of high-frequency climate change that can be compared to those from elsewhere in the region, such as the Palmer Deep on the western margin of the Antarctic Peninsula (Domack et al., 2001).

The second drilling site targets Tertiary strata that should record climate change and the associated faunal and floral changes as the cryosphere evolved in the Antarctic Peninsula region. This site is intended to sample the acoustically layered strata that occur immediately downdip of
Seymour Island (Fig. 4). These strata lie below a major unconformity predicted to mark the boundary between preglacial sediments and overlying strata that show abundant evidence of glacial influence. Seismic stratigraphy and correlative strata exposed onshore suggest that this sequence should consist of upper Eocene through Oligocene strata. The onshore strata are extremely fossiliferous (Zinsmeister et al., 1989), and the more distal offshore strata should provide greater details about the faunal and floral changes that occurred as the Antarctic ice sheet grew larger, closing the last ice-free refugia at the northern tip of the Antarctic continent. Paleontological analyses of the uppermost part of this section will provide age constraints on the onset of glaciation. The sites planned for SHALDRIL's second season lie further updip towards Seymour Island (Fig. 4). They will sample the overlying glacially influenced section and will further constrain the timing of the expansion of the ice sheet. To obtain the best possible paleontologic record from each of these Neogene targets, SHALDRIL aims to sample the glacial-marine units, as identified by seismic facies, rather than the unconformities themselves.

The third hole to be drilled in 2005 targets a Pleistocene grounding-zone wedge and its record of ice flow during the last glacial maximum. We currently lack data for studying the processes by which sediments deform under ice sheets. It is extremely difficult to obtain core samples of modern till because of the extreme thickness of ice moving over that till; however, the previously ice-covered Antarctic conti-

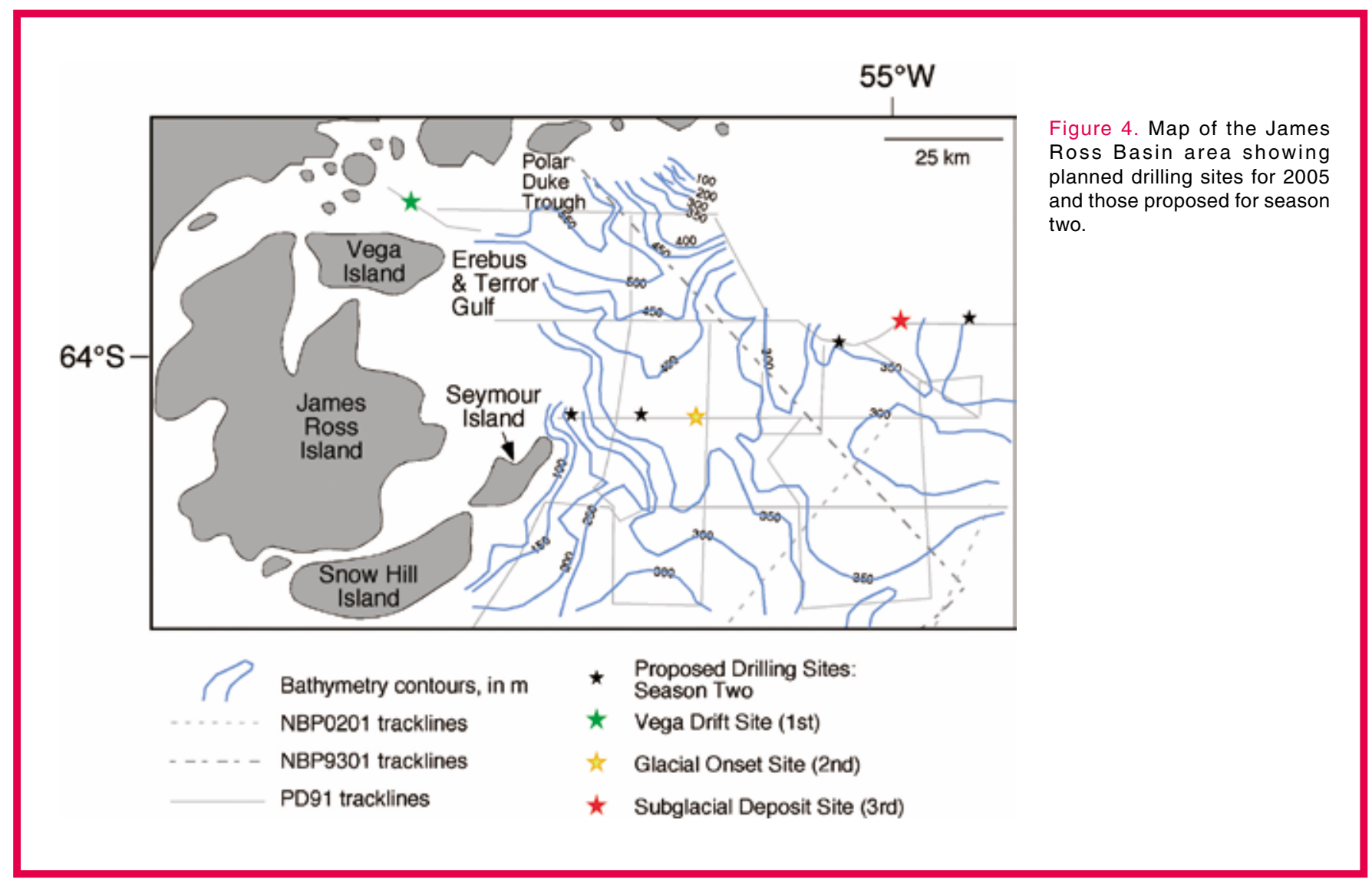


nental shelf provides an ideal place to obtain such samples. The succession within the upstream portion of a wedge should contain changes in ice-bed interaction, from the initiation of bed deformation and streaming to the retreat of the ice stream. A spectacular grounding-zone wedge from the last glacial maximum occurs near the seafloor in close proximity to the other drilling sites (Fig. 4). Coring glacial diamictons is notoriously difficult, but the sampling apparatus that we are bringing for SHALDRIL should be able to recover the first high-quality, long core samples of a grounding-zone wedge deposit.

Ice conditions might not allow drilling at any of these sites, but the entire continental shelf around the Antarctic Peninsula is being considered for alternate sites. Seismic data can be collected during the drilling cruise if needed for selecting alternate sites.

\section{Future Plans}

Over the last few years, the SHALDRIL group has encountered more difficulties than ever imagined in trying to bring together the technologies of an icebreaker and a shallow coring system. We have had to improvise and learn as we go; however, we believe that we have overcome as much as possible and can live with the remaining difficulties.

SHALDRIL will complete its first leg on 23 April 2005. Assuming that we succeed at bringing back core, a workshop will be held at the Antarctic Research Facility in Tallahassee, Florida (U.S.A.) in August 2005, to display the cores to the scientific community and invite proposals for studying them. Either way, we expect to sail again soon on SHALDRIL II to complete the drilling offshore James Ross Island.

For more information, including daily postings from the cruise, please see http://shaldril.rice.edu/.

\section{Acknowledgements}

Other scientists currently involved in this first SHALDRIL cruise include S. Bohaty, P. Manley, F. Weaver, and J. Zachos. We thank the dedicated staff at Raytheon Polar Services Company for helping to make SHALDRIL possible. We are supported by the U.S. National Science Foundation Office of Polar Programs.

\section{References}

Domack, E., Leventer, A., Dunbar, R., Taylor, F., Brachfeld, S., Sjunneskog, C., and ODP Leg 178 Science Party, 2001. Chronology of the Palmer Deep site, Antarctic Peninsula: a Holocene paleoenvironmental reference for the circum-Antarctic. The Holocene, 11:1-9.

SHALDRIL Steering Committee, 2001. SHALDRIL: $A$ Shallow Drilling System to Investigate Antarctica's Climate History: Tallahassee (AMGRF, FSU).

Zinsmeister, W.J., Feldman, R.M., Woodburne, M.V., and Elliot, D.H., 1989. Lower Cretaceous/early Tertiary transition on Seymour Island, Antarctica. $J$. Paleontol., 63:731-738.

\section{Authors}

J. S. Wellner, Department of Earth Science, Rice University MS-126, 6100 Main Street Houston, TX 77005, U.S.A., e-mail: jksmith@rice.edu

J. B. Anderson, Department of Earth Science, Rice University MS-126, 6100 Main Street Houston, TX 77005, U.S.A.,

S. W. Wise, Department of Geological Sciences, 108 Carraway Building, Florida State University, Tallahassee, FL 32306-4100, U.S.A.

\section{Figure Credits}

Fig. 1 photograph from http://www.polar.org/science/ marine/images/nbp_images/ship_cape_royds.jpg.

Fig. 2 Photo by A. Lowe.

All other figures courtesy of SHALDRIL.

\section{Related Weblink}

http://shaldril.rice.edu/

\section{Expedition Update}

The first SHALDRIL cruise ended on 23 April 2005. Due to unexpected weather conditions, the first drilling site was moved to Maxwell Bay in the South Shetland Islands. A Holocene section of $108 \mathrm{~m}$ of core was recovered there, which will allow insights into the climate changes that have occurred at the tip of the Antarctic region. Due to the cruise being well past the optimal season, storms and ice were encountered. Weather conditions as well as some equipment bugs prevented recovery and sampling of the older sections this year. However, experience gained during this cruise will prove to be valuable planning for the next expedition in 2006. Readers interested in the full cruise report, may request it by e-mail to Julia Smith Wellner (jksmith@ rice.edu). 